\title{
Gradhiva
}

GRADHIV

Revue d'anthropologie et d'histoire des arts

$2 \mid 2005$

Autour de Lucien Sebag

\section{Premiers groupes}

\section{Lucien Sebag}

Salvatore D'Onofrio (éd.)

\section{OpenEdition}

\section{Journals}

Édition électronique

URL : http://journals.openedition.org/gradhiva/514

DOI : $10.4000 /$ gradhiva. 514

ISSN : 1760-849X

Éditeur

Musée du quai Branly Jacques Chirac

Édition imprimée

Date de publication : 1 novembre 2005

Pagination : 134-135

ISBN : 2-915-133-10-7

ISSN : 0764-8928

\section{Référence électronique}

Lucien Sebag, "Premiers groupes », Gradhiva [En ligne], 2 | 2005, mis en ligne le 10 décembre 2008,

consulté le 15 septembre 2020. URL : http://journals.openedition.org/gradhiva/514

Ce document a été généré automatiquement le 15 septembre 2020.

(c) musée du quai Branly 


\section{Premiers groupes}

\section{Lucien Sebag}

Salvatore D'Onofrio (éd.)

\section{NOTE DE L'ÉDITEUR}

Le document ci-contre sur les « premiers groupes » témoigne des premiers pas de Sebag chez les Ayoré, d'abord à Fortin Ingavi et probablement aussi dans d'autres endroits du Chaco central, ensuite à Maria Auxiliadora dans le département du haut Paraguay (Boquerones à l'époque), où deux groupes (les Ghidaigosode et les Gaaigosode, respectivement « les gens des campements » et « les gens des champs ouverts ») venaient d'être transplantés hors de leurs territoires traditionnels. Les cahiers de Sebag ne nous permettent pas de fixer les dates ni la longueur de ses séjours dans ces deux localités, mais la liste des premiers groupes qu'il dresse dans ces lieux, et dont nous avons en partie fait la généalogie quarante ans après, correspond à quelques-uns des Indiens rencontrés à Fortin Batista par Branislava Susnik. Parmi les gens de ces groupes, dont quelques personnes sont encore vivantes, nous nous limitons à signaler la présence du chef Eoi et de l'une de ses femmes Kejnéi ainsi que d'Acui, un chamane du groupe Gaaigosode, que Sebag photographie et auprès duquel il commence l'enquête sur le chamanisme ayoré publiée dans L'Homme après sa disparition (« Le chamanisme ayoréo ", L'Homme, V(1), janvier-mars 1965 : 7-32 ; (2), avril-juin 1965 : 92-122). La photographie qui illustre ces listes représente une scène ludique de corps à corps où les Ayoré faisaient preuve d'une adresse particulière (quelques belles images de cette lutte rituelle devaient être prises plusieurs années plus tard, en 1969, par Walter Regehr dans le campement de Faro Moro).

S. D'O. 
Pages manuscrites d'un des cahiers de Lucien Sebag.

Goupe A

Liste vecullue en Ingavi

1) Anoi (carique) - 2) Uoye Ke jai

3) Daari 4) Figicli 5) Duiytai 6) Sidali

7) Amadugu 8) Ka Tojaito -9) Naghaani
2) 10) Usugui
3) 12 Kaaghate
11 Kohigomi
13 Afidi

Goupe B

1) Wuasi (caciques Dagoi ${ }_{3}$ Ador

4) Aguei 5) Baquet .6) Tousude

7) yokaitu 8) yakusé

10) Yookoai 11) Duighai

2) 121 13) thaa tai

15) Elaber 16) G (7) Kuraii

i9) Paconge 19/KuKivi 201 Tohomega

21)

23) Wuasto 24) Shoomic

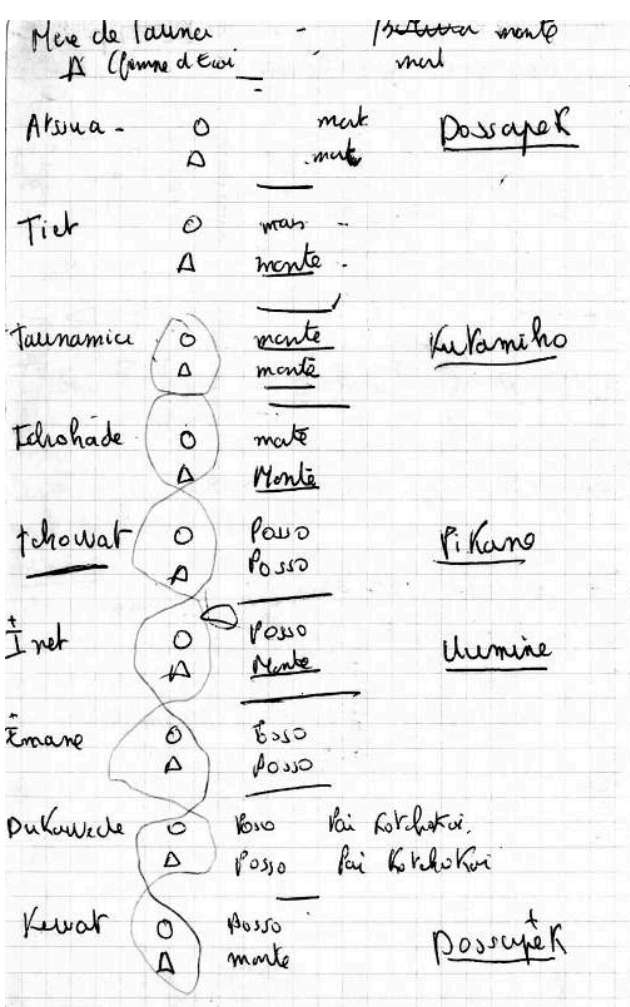

(c) Laboratoire d'anthropologie sociale, fonds Sebag 